\title{
El cronotopo del siglo XIX a través de dos novelas de la tradición literaria colombiana: María (1867) de Jorge Isaacs y La casa de las dos palmas (1988) de Manuel Mejía Vallejo
}

\author{
The 19th Century Chronotope through Two Colombian \\ Literary Tradition Novels: María (1867) by Jorge Isaacs and \\ La casa de las dos palmas (1988) by Manuel Mejía Vallejo \\ O cronotopo do século XIx a traves de duas novelas da \\ tradição literária colombiana: Maria (1867) de Jorge Isaacs \\ e A casa das duas palmas (1988) de Manuel Mejía Vallejo \\ Edilson Silva Liévano ${ }^{1}$ \\ David Alejandro Roa Ramírez ${ }^{2}$
}

\section{Resumen}

En la medida en que la literatura tropologiza, trama y crea representaciones sobre la vida, los hechos históricos o personajes del pasado, puede contribuir o ser solidaria con otros discursos como el de la historia para caracterizar o comprender una época. Así, el siglo xix colombiano aparece como el más romántico de los siglos porque en él se funda el proyecto de nación y a este propósito contribuyeron profundamente los intelectuales de la época como literatos, juristas, periodistas, políticos, entre otros. Tras un ejercicio investigativo, este trabajo analiza la novela María en cuanto novela que hegemoniza las estructuras coloniales como programa nación; de igual manera, descubre en La casa de las dos palmas la epopeya de la cultura paisa en la construcción de país durante el siglo xIX.

Palabras clave: Cronotopo, modernidad, colonialidad, tropologización, historia, mentalidad.

\section{Abstract}

In the form in which literature tropologizes, plots and creates representations about life, historical facts or people from the past, that can contribute or be supportive with other discussions as to how history can promote the characterization or understanding of an era. In this regard, Colombian 19th century appears as the most romantic centuries because during this period the nation's project was founded, and it greatly impacted the intellectuals of the era such as writers, jurists, journalists, and politicians, among others. After doing an investigation, this study analyzes the novel Maria, which dominates colonial structures, such as a nation program. In the same way, in La casa de las dos palmas is discovered the epic "paisa" culture in the development of the country during the 19th century.

Keywords: Chronotope, modernity, colonialism, tropology, history, mentality.

\section{Resumo}

Na medida em que a literatura tropologiza, trama e cria representações sobre a vida, os feitos históricos ou personagens do passado, pode contribuir ou ser solidaria com outros discursos, como o da história para caracterizar o compreender uma época. Assim, o século xIx colombiano aparece como o mais romântico dos séculos, porque nele se funda o projeto de nação, e a este propósito contribuem profundamente os intelectuais da época como literatos, juristas, jornalistas, políticos, entre outros. Depois dum exercício investigativo, este trabalho analisa a novela Maria, em quanto novela que hegemoniza as estruturas coloniais como programa nação; do mesmo jeito, descobre na Casa das duas palmas a epopeia da cultura "paisa" na construção de país durante o século xIX.

Palavras-chave: Cronotopo, modernidade, colonialidade, tropologização, história, mentalidade.

Artículo recibido el 05 de abril de 2015 y aprobado el 26 de junio de 2015

1 Licenciado en Filosofía y Letras (Universidad de la Salle); máster en Literatura Hispanoamericana (Instituto Caro y Cuervo), especialista en Formación de Actores para Teatro, Cine y Televisión (Escuela de Artes Cinematográficas, ser). Docente investigador Fundación Universitaria Los libertadores y Universidad Pedagógica Nacional. Este artículo se presenta como resultado de una investigación al seminario Historia Contemporánea de América Latina, bajo la orientación del doctor Karl Böhmer Muñoz, en el marco de los cursos del Doctorado en Cultura y Educación en América Latina, elap. Fecha de elaboración agosto de 2014. palabreros@hotmail.com

2 Universidad Pedagógica Nacional, Bogotá, Colombia. Correos electrónicos: palabreros@hotmail.com; davandroll@hotmail.com 


\section{Introducción}

Las novelas María (1867) de Jorge Isaacs y La casa de las dos palmas (1988) de Manuel Mejía Vallejo nos permiten hacer una lectura de la estructura social de finales del siglo xix y del tránsito hacia el siglo xx. Dicha estructura no quedó atrás, más bien es nuestra intuición que la colonización no se ha asimilado en su totalidad, por el contrario, continúa operando como axiología configuradora de la nacionalidad colombiana o como proyección del mundo europeo, lo que resulta especialmente problemático para comprender el presente en relación con su movimiento histórico. Como objetivo general la investigación se propone caracterizar las estructuras sociales, políticas, religiosas, culturales, representadas en las novelas a partir del orden de configuración que otorga la categoría central de cronotopo.

El trabajo parte de la idea de que la novela, en especial la novela histórica, constituye un punto de vista particular sobre la historia. Para ello, se asume la categoría principal de cronotopo planteada por Mijaíl Bajtín, por considerar que dicha categoría nos brinda un puente entre el espacio tiempo asimilado por la obra literaria y sus relaciones históricas con el espacio tiempo de la época. A partir del filósofo e historiador estadounidense Hyden White, se toma la idea de superar la crítica histórica basada en periodizaciones, mediante el uso de la categoría de cronotopo, pues es a través de sus múltiples relaciones como puede deslizarse el objeto de estudio hacia aproximaciones más multidisciplinarias e interdisciplinarias. Como hipótesis central, este trabajo plantea que la colonización en cuanto axiología no asimilada ${ }^{3}$ resurge en diferentes momentos después de la independencia, lo que genera formas de pensar, actuar o ser, que son objetivadas en representaciones concretas como los discursos sobre el pasado, bien sea históricos o literarios. Para ello, se estudian dos novelas del campo literario colombiano que distan más de un siglo la una de la otra y que, al pertenecer al canon literario, reproducen constantemente

3 Por "no asimilada" entendemos: no digerida, no culminada, completada en su totalidad. la axiología de la colonización, hasta el punto de naturalizarla desde su lugar de enunciación.

\section{Cuestiones teóricas}

El cronotopo, concepto propuesto por Mijaíl Bajtín, es definido como "la conexión esencial de relaciones temporales y espaciales asimiladas artísticamente en la literatura" (Bajtín, 1989, p. 237). Este concepto nace de una asimilación metafórica en la literatura de la teoría de la relatividad. Como es evidente, su etimología remite directamente a la noción de tiempo (cronos) y espacio (topos) y se constituye como una unidad artística indisoluble en la cual el aspecto temporal comprenderá una relevancia sobresaliente. El autor ruso sugiere, además, una diferenciación entre el cronotopo histórico real (sobre el cual enfatiza la falta de reflexión) y el cronotopo artístico literario, que es el que convoca su mayor interés. Este cronotopo se presenta de manera inteligible, como un todo indisoluble en el que "el tiempo se condensa [...] se comprime, se convierte en visible desde el punto de vista artístico; y el espacio, a su vez, se intensifica, penetra en el movimiento del tiempo, del argumento, de la historia" (p. 238). Así, el cronotopo supone la categoría temporal como una cuarta dimensión del espacio, pues "los elementos de tiempo se revelan en el espacio, y el espacio es entendido y medido a través del tiempo" (p. 238). Por estas razones el cronotopo adquiere una importancia esencial en la conformación de los géneros dado que permite la unidad artística del relato, la asimilación del espacio, la progresión temática, así como la asimilación de la evaluación de la historia en los dos momentos más importantes del relato: el inicio o apertura argumental y el cierre argumental donde la situación de los personajes cobra mayor importancia para la resolución de la historia.

Las categorías de historia y ficción pueden identificarse con los cronotopos histórico real y artístico literario, respectivamente. El cronotopo real histórico está referido a la asimilación hacia el pasado del mundo real de una época y una sociedad determinadas en la literatura; así, por ejemplo, cuando aborda brevemente la reflexión sobre el cronotopo 
del cuarto de recibimiento, en el que tenían lugar aspectos del mundo real social y político de un momento histórico, el autor afirma que "la época se hace concreta-visible" (p. 398). Por otro lado, el cronotopo artístico literario puede asociarse con la idea de ficcionalidad en tantoconstituye los argumentos novelescos; para el mismo caso del cronotopo del salón de recibimiento, Bajtín señala que la época se vuelve "argumental-visible", puesto que el componente de lo personal y particular que acontece en dicho espacio está condensado en la obra como argumento.

A partir de los planteamientos hechos por Bajtín se puede entrever que lo real-histórico está constituido como una ficción, pues se compone de una serie de imágenes que nacen a partir de la intención de narrar un acontecimiento y que, por tanto, ya no son el acontecimiento mismo. Además, Bajtín anuncia que el estado de las imágenes es inexistente sin la lógica espacio-temporal que les provee el cronotopo: la narración se construye con base en él, en torno a él. Asimismo, ante la diversidad de cronotopos que pueden confluir en una obra, Bajtín señala:

Los cronotopos pueden incorporarse uno a otro, pueden coexistir, combinarse, sucederse, compararse, confrontarse o encontrase complejamente interrelacionados [...] El carácter general de esas interrelaciones es dialogístico [...] Dicho diálogo entra en el mundo del autor, del intérprete, en el mundo de los oyentes y los lectores. (p. 402)

Para Hayden White, "si algo no está escrito, no es historia" (2011, p. 28). Los historiadores pueden apropiarse de la historia en la medida en que por historia entienden ese aspecto del pasado de la forma como ellos escriben y lo estudian, pero los historiadores no son los dueños ni tienen atribuciones exclusivas sobre el pasado, pues ese mismo derecho lo pueden reclamar los escritores de literatura. De hecho, White analiza tres movimientos culturales del siglo XIX europeo en relación con el "cambio histórico", el romanticismo, el historicismo y el realismo, sin discriminar entre pensadores filósofos, escritores o historiadores, y encuentra que los tres tuvieron que resolver la pregunta en común de cómo ordenar la experiencia en relación con tres aspectos fundamentales: "los datos del proceso físico-natural, los datos de la conciencia humana individual y los datos del proceso social" (p. 173). Todos articulados desde un eje común, la conciencia humana, en relación con la vida social.

Pero los románticos, los realistas y los historicistas, coinciden que la vida humana social implica otras tantas obligaciones como beneficios en la tarea de conquistar una humanidad íntegra. La diferencia en ellas reside en el grado de optimismo con que plantean la tarea. (p. 177)

Hayden White trata de salvar la oposición entre historia y ficción, tal oposición no existe:

Las historias no se viven, no existe algo así como la historia verdadera. Las historias se cuentan o se escriben, no se encuentran. Y en relación con una historia verdadera, esto es virtualmente una contradicción en sus términos. Todas las historias son ficciones, y por supuesto, que son ciertas, solo en un sentido metafórico, en el sentido que puede serlo una figura del lenguaje. (p. 36)

Esta afirmación de Hayden White compromete sus presupuestos. Según ella, White piensa que en la base de todo lenguaje hay una estructura "tropológica” desde la que nos representamos el mundo, y según lo analiza en uno de sus ensayos, "Pluralismo histórico y pantexualismo", las historias no son verdaderas o falsas, sino, más bien, más o menos inteligibles, coherentes, consistentes, convincentes y así sucesivamente. La diferencia entre una escritura y otra también es una diferencia de grado en la forma como lo afirmó en el ensayo "La supresión de la retórica":

La escritura literaria debería ser vista como lo que de una manera evidente parece ser, es decir, solo una especie particular de escritura en la cual el acto figurativo se presenta como un elemento de su contenido evidente, y también como característica dominante de su forma. (2011, p. 513)

Como lo sostiene White, la historia no es tanto el conjunto de los hechos del pasado, ni tampoco nuestro estudio de ese objeto, "es también y aun pri- 
mariamente, cierto tipo de relación con el pasado mediado por un tipo distintivo de discurso escrito" (2003, p. 141). Este discurso trata acerca de "la presunción de la existencia del pasado como algo sobre lo que es posible hablar significativamente" (p.142). White afirma que el problema del historiador no es metafísico ni epistemológico, es decir, de si el pasado existe o de si lo podemos conocer, de hecho, existen historias, acontecimientos, estructuras que llegan a ser históricas porque son representadas como objetos de una escritura específicamente histórica. Para White, la información del pasado puede ser considerada como "archivística", no es aún "discurso histórico" y puede ser tomada por cualquier disciplina tanto humana como científica. Es por eso que la historia debe ser escrita antes de poder ser leída, cantada, bailada, filmada, actuada. Así que, en los dos caminos posibles para acercarnos el pasado, tenemos "la investigación historiográfica", que White entiende "como el estudio por parte de los historiadores de un archivo que contiene información acerca del pasado" (p. 154); o la "escritura histórica" que entiende como la "composición por parte del historiador de un discurso y su traducción en forma escrita" (p. 155). El historiador lo que hace es producir interpretaciones de cualquier información acerca del pasado.

Así que, si decidimos a través de dos novelas ver parte de la solidaridad con el pasado de un siglo, es porque esas dos obras, siguiendo la estructura que plantea White entre historia y literatura, primero, nos "representan" a través de su forma composicional (crónica, novela, cuento, etc.) una mirada sobre el pasado; segundo, ese pasado es "trasformado", es decir, es presentado a partir de un conjunto de elecciones que le permiten a los escritores y novelistas construir la trama, esto es, organizar los acontecimientos, elegir un inicio, un nudo o un desenlace, cualquiera que sea el orden temático de su argumento; y tercero, porque ese aspecto del pasado se nos es constituido o presentado como el tema de cualquier argumento formal que pude aducirse para construir su significado. A todas estas operaciones, White las denomina "tropologizar los acontecimientos". De ahí que la narrativa literaria, tanto como la histórica, esté emparentada por este aspecto del lenguaje que pretende aprehender el mundo, dotarlo de sentido.

White encuentra que la categoría de cronotopo le permite al historiador superar la idea de "periodo". En un texto de 1987, "El siglo XIX como cronotopo", en el que sugiere maneras en que el cronotopo podría ser aprovechado para un análisis cultural e histórico en general, escribe:

Para los estudios históricos, la idea de cronotopo tiene muchas ventajas sobre la noción de periodo. $\mathrm{Al}$ ser una combinación de categorías temporales, espaciales, sociotemporales, el cronotopo exige un mayor grado de especificidad y de concreción referencial que la de período [...], el cronotopo es directamente accesible al análisis a través del estudio del bagaje documental de una sociedad y del testimonio individual de los escritores, novelistas, poetas, periodistas, escritores de epistolarios o de autobiografías, científicos, filósofos y demás cuyas obras permitan el trazado de una cantidad de mapas mentales de un determinado tiempo, espacio y situación cultural y la construcción de la leyenda que todos dieron por sentada como el código común que compartieron tanto como para crear como para leer el terreno de la conciencia que de hecho ocupaban. (White, 2011, p. 422)

Así que, tras esta breve disertación acerca de la categoría central de análisis, queda abierto el camino para el estudio del cronotopo del siglo XIX colombiano. Se comprende, entonces, que lo que se analiza no es en sí las novelas como obras aisladas, sino que estas son asumidas como textos para la construcción de un discurso histórico del cronotopo del siglo XIX en Colombia. La ruta metodológica comprende la lectura atenta de las novelas, la documentación sobre el pensamiento político, económico, socioeconómico del siglo XIX, sobre todo porque es nuestra consideración que dicho siglo no es aún un hecho del pasado (lejano, remoto), sino que guardamos una estrecha relación con él hasta el punto de ser constitutivo de nuestro presente. Una precisión más: "La noción del cronotopo nos hace reflexionar acerca de las ambivalencias psicológicas, morales y 
estéticas, políticas, económicas y epistemológicas de una época" (White, 2011, p. 425).

\section{Metodología}

Para las dos novelas se elaboró un perfil de sus escritores como punto de referenciadel lugar de la enunciación en relación con la época que se narra en la novela, lo cual constituye parte del cronotopo real histórico; luego, se analizó el cronotopo de ficción presente en la novela en sus dos componentes: el tiempo y el espacio. En relación con estos, se analizaron tres elementos estructurales del relato: los personajes, la historia representada y el manejo del relato. Para el eje del tiempo, los elementos posibles a encontrar fueron: personaje (tiempo psicológico, éticas civiles, axiologías, tipología de héroe novelesco); historia representada (hechos, datos, mentalidades); manejo del relato (tiempo del relato, tiempo natural, argumento y trama). En relación con el espacio se observaron los siguientes elementos: personaje (forma de relacionarse con los lugares o sitios); historia representada (espacios cargados de representación simbólica); espacio de ficción (inicio argumental, final argumental, argumento y trama, lugares del cronotopo). Son estos puntos de referencia que actúan como códigos sociales y textuales presentes en la novela, cargados de significación, que al ser puestos en relación con la historia nos permiten construir una mirada crítica sobre cada novela. Muchos elementos de lectura serán incluidos solo en la medida en que sean necesarios para demostrar una conjetura interpretativa como resultado del recorrido textual de la novela. Esta conjetura, además, indica el sentido que se quiere privilegiar en el análisis de la novela, pues la misma no agota la totalidad de la obra.

\section{Conjetura sobre la novela María}

La novela María (1867), del escritor Jorge Isaacs, es una novela de la diferencia colonial: geopolítica, territorial y racial. El relato en esta novela constituye la continuación de la mentalidad colona en el primer siglo de la formación de la república colombiana a través de un programa de nación que se evidencia en los diferentes aspectos del mundo narrado tales como: la organización social, la representación simbólica de los espacios; los imaginarios de lo masculino y lo femenino; la construcción de la alteridad como característica diferenciadora de raza; la realización del capitalismo en las formas de la propiedad, la industria, la explotación minera, el comercio exterior con Jamaica; la continuación de un proyecto de europeización en las relaciones culturales con Inglaterra o en sus referentes siempre foráneos de distinción de clase que se evidencian en las formas arquetípicas de vestir, los códigos de conducta y las lecturas.

\section{Contextualización}

La novela María ocupa el lugar privilegiado de "novela nacional" de final del siglo XIX, como lo sostiene Doris Sommer. Con ello, se refiere a "aquel libro cuya lectura es obligada en las escuelas secundarias como fuente de la historia nacional y orgullo literario" (2004, p. 20). Esta literatura está profundamente ligada a la legislación de las recientes repúblicas latinoamericanas, o, como lo denomina Ángel Rama (1998), a "La ciudad letrada", donde los escritores fueron al mismo tiempo funcionarios públicos u ocuparon incluso el lugar de presidentes, que para el caso latinoamericano es relevante. Esto quizá hace que los escritores estuvieran más "involucrados en querellas partidistas que en una crítica social trascendental” (Sommer, 2004, p. 20). Es decir que, si esto es así, como podría estudiarse desde la concepción de habitus planteada por Pierre Bourdieu, los escritores habrían escrito en su mayoría desde la comodidad de su lugar de enunciación ${ }^{4}$.

4 Como tributo a su posición central en el campo cultural, encontramos un homenaje que le hace el Banco de la República de Colombia con la emisión, en el año 2000, del billete de denominación de 50000 pesos: "Con esta edición del billete de cincuenta mil pesos el Banco de la República quiere rendir homenaje a Jorge Isaacs, quien inmortalizado por su novela María, fue mucho más que un autor literario. Este hombre multifacético se desempeñó además, como político, militar, minero y educador. Sin embargo, su faceta más conocida a través del tiempo ha sido la de novelista. Publicó María en 1867, y a finales del siglo la novela ya iba en más de 50 ediciones y había sido publicada en varios idiomas. Moreno Durán, por su parte, sostiene que es la novela latinoamericana más leída en el siglo pasado. Isaacs fue un caso de éxito en la economía globalizada del siglo xIx y es por esto que se rinde este homenaje" 
Jorge Isaacs (Cali, abril 1 de 1837, Ibagué, abril 17 de 1895) ${ }^{5}$ fue hijo de colonos. Su padre, George Henry Isaacs, era un judío de origen inglés que había nacido en Jamaica y que se estableció en el Chocó hacia 1822. Se dedicó a lo que en gran parte se dedicaban los colonos del siglo xix, la explotación minera aurífera, que hasta la actualidad continúa como una práctica artesanal, hoy convertida en política a gran escala bajo el denominativo de la "Locomotora Minera" en el gobierno del presidente Juan Manuel Santos (periodo 2010-2014, reelección, 2014-2018). Luego, tras acumular riqueza con la explotación del oro y los negocios con Jamaica a través del río Atrato, se traslada a Cali y adquiere extensas propiedades de tierra como las haciendas La Santa Rita (1840) y La Manuelita, sede actual del famoso ingenio azucarero homónimo, y luego la hacienda El Paraíso (propiedad de la familia entre 1855 y 1858), que sería la "Casa de la sierra" escenario de la novela María.

Las estructuras del cronotopo real histórico de finales de siglo no solo son interiorizadas por el joven escritor sino naturalizadas en su narración literaria. La sociedad colombiana se establece a partir de una marcada diferenciación en la propiedad privada de la tierra, pero también en todos los elementos de la vida cotidiana cultural. La sociedad patricia colombiana hasta nuestros días está fincada en esa tradición de la propiedad de la tierra y su explotación minera o agraria, de hecho, allí donde la familia Herreros encuentra una mina de oro, el patriarca funda un pueblo, como se relata en la segunda obra de nuestro análisis, La casa de las dos palmas (1988) del escritor antioqueño Manuel Mejía Vallejo (Jericó, 1923), y que no está ausente en la primera novela, María. La actividad minera que viene andando desde la época colonial queda mejor descrita en el siguiente texto del historiador Luis Fernando Molina Londoño.

(palabras del doctor Miguel Urrutia Montoya, gerente del Banco de la República, disponible en http://www.banrep.gov.co/es/ node/6260).

5 Los datos así como el análisis que aquí se hacen pueden contrastarse a partir de la información oficial disponible en el sitio web: http://www.banrepcultural.org/blaavirtual/biografias/isaajorg.htm; recuperada el 12 de abril de 2014
Desde la colonia, el principal producto de exportación del país fue el oro. Con la minería de oro y plata en el siglo xIx, Colombia logró integrarse como república independiente a la economía mundial con un exitoso producto de exportación, configuró una eficaz red de caminos de herradura que animaron el comercio y la colonización de baldíos, creó el ambiente para que numerosas personas desarrollaran habilidades técnicas, empresariales y gerenciales, propició una distribución amplia del ingreso por exportaciones que impulsaron el consumo de bienes manufacturados y permitió la acumulación de capitales que se invirtieron en otras actividades como la banca, los transportes, la agricultura y la financiación del Estado.

No tanto con esclavos, como en el Cauca, sino con mano de obra libre, en Antioquia existió una explotación mayoritariamente familiar o de pequeñas compañías de mineros que originaron una gran dinámica económica y empresarial. Sin embargo, en una región caracterizada desde la colonia por la pequeña minería, a mediados del siglo XIX, se fue abriendo paso la gran empresa, en un intento por aumentar la escala y la productividad del laboreo mediante la incorporación de modelos de organización y sistemas de explotación más eficientes. Surgieron así algunas de las empresas más considerables del país en el siglo xIx. La Sociedad de Zancudo llegó a ser la más grande y rentable de Colombia. (Molina,2011, recuperado el 12 de abril de 2014,en http://www.banrepcultural.org/ blaavirtual/revistas/credencial/junio201)

La formación académica de Jorge Isaacs está marcada por su ingreso a prestigiosos colegios bogotanos entre 1848 y 1852, en los que se formó gran parte de la élite colombiana de finales del siglo XIX e inicios del xx: el colegio el Espíritu Santo (propiedad de Lorenzo Mariano Lleras, figura política influyente durante todo el siglo xx); el colegio San Buenaventura y el colegio San Bartolomé.

\section{Desarrollo de la primera conjetura}

Los movimientos independistas de la reciente República, desde 1810 a 1819, solo representaron 
una independencia, política y geográfica, parcial, respecto a la colonia española y a Europa en general.

La negación de Europa no fue ni en América hispánica ni en la anglosajona, la negación de la europeidad, puesto que en ambos casos, y en tanto que el impulso de la conciencia criolla blanca, se trataba de ser americanos sin dejar de ser europeos; ser americanos, pero distintos a los amerindios y a la población afro-americana. (Mignolo, 200, p. 69)

La tesis que plantea Walter Mignolo es la de una doble conciencia que daría como resultado una doble diferencia colonial: una, frente a Europa, que es puramente geopolítica, el deseo de los criollos blancos y mestizos por gobernarse o tener el control; y otra, que es una diferencia colonial racial, y que a la larga constituye la continuidad de la colonialidad, la perpetuidad del sistema-mundo moderno geocultural que las naciones no abandonaron en su constitución de repúblicas independientes y que se evidencia en aspectos como la organización social en castas, etnias o razas; la estratificación de la sociedad de acuerdo a la economía; la explotación de la tierra así como su tenencia por parte de los amos; la reproducción del saber moderno así como su constante importación que desconoce otras formas de saberes. La idea de civilización asociada al saber, el derecho, la ciencia, el progreso en detrimento de las otras civilizaciones consideradas por Europa como mundos bárbaros. Una desconsideración de todo lo diferente que ha defendido el imaginario hegemónico de lo europeo. Así que la diferencia colonial interna no podía terminar sino en la exclusión de los otros no blancos o mestizos, como han sido históricamente nuestras formas o el lugar que les hemos asignado a los aborígenes, a las comunidades afrocolombianas, a la mujer, a las minorías sexuales, siempre en los niveles más bajos de la escala social. Son esas formas de considerar lo civilizado, lo europeo, lo bello, el saber, la técnica, el progreso, la cultura, los elementos que ameritan una reflexión histórica que conduzca hacia el desarme de la matriz blanca-moderna-colonial que nos habita aún y se reproduce contantemente en los objetos simbólicos como la novela María, cuyas constantes reediciones o lecturas apologistas exalta una supuesta estética nacional que nos habría puesto a tono con el mundo de finales del siglo XIX, así como en el sinnúmero de trasvases y adaptaciones al cine y la televisión ${ }^{6}$.

Los análisis sobre la novela generalmente se centran en el aspecto romántico de la obra o esteticista de su lenguaje. Así que, si solo se observa el argumento amoroso que la ha empoderado como la novela fundacional de Colombia, y que ha sido el elemento explotado en las múltiples adaptaciones al cine,la novela se resuelve en el siguiente argumento. La novela María relata la historia de amor entre Efraín y su prima María, llamada Ester antes de su conversión del judaísmo al catolicismo. Este amor encuentra como oponentes a lo largo de la trama varios actantes: primero, la separación temprana, cuando eran apenas unos niños (Efraín fue llevado de Cali a Bogotá para educarse en el Colegio del Espíritu Santo); luego, la enfermedad de María, heredada de su madre, que las llevó a las dos a la muerte; después, la oposición de su padre para que estos se casaran; por el mismo tiempo, la petición de Carlos, hijo de otro hacendado, de la mano de María, con el fin de unir las familias y hacer crecer el abolengo; además, el determinante viaje de Efraín a Inglaterra para iniciar sus estudios de una carrera de

6 Según una revisión documental realizada por el investigador colombiano César Alzate, la primera adaptación que se conoce es del año 1918, producida por el mexicano Rafael Bermúdez Sataraín. Sin embargo, Hernando Salcedo Silva insinúa la posibilidad de un primer bosquejo fílmico de María ya en el año 1889, año en que se documenta la primera filmación en nuestro territorio; luego, vendrían otras adaptaciones: en 1918, por Rafael Bermúdez Sataraín, de la cual se dice que fue la primera obra colombiana en inspirar una película; en 1922, se realiza un trasvase gestionado por Antonio J. Posada, un ex fraile franciscano, película de la que solo se conservan 25 segundos en los archivos del Patrimonio Fílmico Colombiano, dirigida por el inmigrante español Máximo Calvo Olmedo; en 1966, Enrique Grau hace un nuevo largometraje, al que le sigue una adaptación de Tito Davison de 1972, coproducción colombo-mexicana, que es una de las versiones más vista desde los setenta y cuya trama central enfatiza el amor entre Efraín y María con algunas variaciones en los lugares. La adaptación más reciente se filmó en Puerto Rico, en 2012, producida por el mexicano Fernando Allende, que ya había hecho el papel del adolescente Efraín en la adaptación de 1972, y en la que ahora interpreta el personaje del padre de Efraín, interpretado éste, a su vez, por su hijo Adam Allende. 
prestigio, medicina ${ }^{7}$; finalmente, la muerte de María antes del regreso prematuro de Efraín de Londres. Esta es la trama que siempre se ha visibilizado y a la cual se le da mayor importancia. Sin embargo, no como subtrama (sería un error considerarlo de esta manera),sino como forma arquitectónica de la obra, la novela María es el relato de un modelo de nación centrado en la diferencia colonial. Ese carácter nacionalista es lo que podríamos denominar su sentido romántico más genuino, pues la constitución de los héroes, más allá de la herencia de un romanticismo llorón ${ }^{8}$ (de la expresión máxima de la subjetividad, los sentimientos, los deseos amorosos, los héroes románticos), más bien no se consolida como tal. La muerte de María no es por amor, sino por causa de una epilepsia, lo cual tampoco la hace una heroína trágica, pues no hay nada de héroe trágico en que un ser humano muera por epilepsia, es solo un hecho circunstancial, natural. Efraín como héroe romántico tampoco renuncia a nada, no lucha por el amor, solo se limita a seguir las determinaciones de su padre quien, una vez advierte que los dos jóvenes se aman, decide que lo mejor será que se casen tan pronto como Efraín termine sus estudios de medicina en Inglaterra. Así pues, el romanticismo respecto a los héroes queda referido a la expresión subjetiva de sus mundos nostálgicos del amor, mientras que al cronotopo central en que se realiza queda referida la constitución de un relato de nación existente en el que se muestran las diferentes clases sociales, la hegemonía de la raza blanca como consolidación del poder dominante, la religiosidad católica como elemento de control del sujeto que

7 Debe tenerse en cuenta que para la fecha era imposible estudiar medicina en Colombia, pues la Universidad Nacional de Colombia se creó bajo el periodo de la República Liberal por ley del 22 de septiembre de 1867.

8 Una de las influencias que se asocian al romanticismo literario colombiano es el de François-René, vizconde de Chateaubriand (Bretaña, 1768, París, 1884). A quien se considera uno de los maestros e iniciadores del romanticismo francés. Autor de novelas como Atala (1801), que es precisamente uno de los libros que leen las hermanas de Efraín. Según Genaro Rodenas "Atala recoge la idea de la religión como fuente de sensibilidad, asociada a la naturaleza exótica, bárbara incluso, del Nuevo Mundo y la melancolía y las pasiones" (disponible en http://www.cervantesvirtual.com/obravisor/atala-de-chateaubriand-en-la-traduccin-de-pascual-genarordenas-1803-0/html/01d19f68-82b2-11df-acc7-002185ce6064_2.html). se impuso en Colombia desde el siglo xIx; precisamente, los ejes centrales que constituyen la novela como relato romántico fundacional.

\section{María como programa de nación}

Si leemos la novela María como relato de nación, nos encontramos en la semilla germinal de la nacionalidad colombiana a lo largo del siglo xIx. La mujer que hemos creído María como mujer terrenal, la prima real de Efraín, simbólicamente representa la imagen de la madre de Jesús en la cosmogonía cristiana. El relato sobre María constituye un proyecto tanto moral y religioso como arquetípico de lo que debía ser la mujer colombiana para finales del siglo XIX: "En días como aquel María me esperaba siempre en el salón, conversaba con Emma y mi madre, leyendo a ésta algún capítulo de la Imitación de la Virgen o enseñando oraciones a los niños" (1988, p. 78). Se trata de una forma de influir en la subjetividad de los lectores a través de tipos de enunciaciones declarativas; en este caso, María es el arquetipo a seguir. Es por esta razón que María se mantiene siempre virgen, casta, delicada, maternal y religiosa, lo cual genera el arquetipo de mujer que se espera. Para entonces las mujeres no gozaban de derechos políticos, no iban al colegio, solo a la escuela, o se educaban en la casa en oficios como el cuidado del jardín, coser, el cuidado de los hombres, los niños, los enfermos, o aprendían algún arte como tocar guitarra, piano, pintar (para que de paso les diera cierto nivel de diferencia social respecto a la servidumbre de origen esclavista). En la novela María, María, Eloísa y la madre pasan gran parte de su tiempo distribuido en los oficios del costurero, el oratorio, cuidando los niños o tomando lecciones de geografía o gramática, mientras que la servidumbre, como la negra Feliciana (Nay), lo hace en la cocina preparando los alimentos de sus amos. Los hombres, por el contrario, se dedican a lo propio de los hombres de entonces: la administración de la hacienda, la disposición de los recursos, el estudio, la lectura por parte de los amos; mientras que los peones, siempre constituidos por negros, se ocupan del oficio del campo, no lloran y huelen 
a chivo: “- ¿Llorando?, ¿ah feo!, ¿un hombre con miedo?” (1988, p. 53).

Considerar que en la novela Maríase insertan varios tipos de programas es advertir que la estética, los elementos propiamente literarios, están al servicio de una macroestructura que los ordena de acuerdo a los fines racionales de la nación que se quiere construir. Para Santiago Castro Gómez (2003), la formación de los Estados nacionales y la consolidación del colonialismo son fenómenos que están estrechamente relacionados dentro de la consolidación del proyecto de gubernamentabilidad como traducción del proyecto de modernidad. Varios elementos son constitutivos de esta visión: en primer lugar, dice Santiago Castro, "nos referimos al intento fáustico de someter la vida entera al control absoluto del hombre, bajo una guía segura del conocimiento" (2003, p. 146). En la última parte de la novela, Efraín ha viajado a Londres para estudiar medicina con el fin de poder curar la epilepsia que aqueja a su amada María. Así que la naturaleza encuentra su adversario en la ciencia, su pretensión de dominación. Sin embargo, en la novela, aún no es el conocimiento técnico o científico lo que prima, sino el conocimiento de la religión el que permite someter las pasiones o las conductas bajo el modelo casi fabulesco medieval. Si María imita a la Virgen todas las mujeres deberían imitar a María. Los amos blancos son garantes o enfatizan el cumplimiento de una estrecha obediencia a la religión católica.

El narrador intradiegético, Efraín, nos permite conocer los orígenes de la familia, profundamente cristiana y española. A su vez el relato familiar pretende ser elevado a norma nacional. Como ya hemos dicho, su padre proviene de Jamaica, y son de origen judío, pero convertidos al cristianismo:

Muy jóvenes habían venido juntos a Sur América; y en uno de sus viajes se enamoró mi padre de la hija de un español, intrépido capitán de navío, que después de haber dejado el servicio por algunos años, se vio forzado en 1819 a tomar nuevamente las armas en defensa de los reyes de España, y que murió fusilado en Majagual el 20 de mayo de 1820.
La madre de la joven exigió por condición para dársela por esposa que renunciase él a la religión judaica. Mi padre se hizo cristiano a los veinte años de edad. (1988, p. 11)

Tras ese relato exaltado de su abuelo español, Efraín cuenta el origen de María. Ella era hija del primo antillano de su padre, Salomón, que había enviudado de su esposa Sara, por lo que quedó huérfana a la edad de tres años; en ese entonces se llamaba Ester, pero luego pasaría a ser María. Las palabras de Salomón a la hora de entregar en adopción a su hija fueron: "Las cristianas son dulces y buenas, y tu esposa debe ser una santa madre. Si el cristianismo da en las desgracias supremas el alivio que tú me has dado, tal vez yo haría desdichada a mi hija dejándola judía" (p. 12). Este mismo dictado aplica o se promueve en el relato de la nación a través de otras historias como la de la esclava Feliciana, madre del "negro Juan Ángel”. Jorge Isaacs dedica desde el capítulo XL al XuIV al relato de Nay y Sinar, una narración sobre cómo una princesa hija de reyes africanos terminó convertida en esclava en la hacienda El Paraíso, porque le sirve a su propósito de ejemplificar el papel de los sacerdotes como misioneros evangelizadores. Resulta curioso que en otros momentos de la novela el narrador haga un esfuerzo casi de transcripción fonética para decirnos cómo hablan los negros bogas chocoanos, pero aquí, contrario al aparente amor que le tienen él y su familia a los esclavos, no cede la voz a la esclava Feliciana, sino que es él quien cuenta la historia del sujeto subalterno, haciendo antes una aclaración peyorativa: "Pero he aquí su historia que referida por Feliciana, con rústico y patético lenguaje, entretuvo algunas veladas de mi infancia" (p. 116). En otras ocasiones también se referirá a ellos como brutos.

También dice Santiago Castro que la "modernidad es una máquina generadora de alteridades que, en nombre de la razón y el humanismo, excluye de su imaginario la hibridez, la multiplicidad, la ambigüedad y la contingencia de las formas de vida concreta" (2003, p. 145). La novela María es precisamente el espacio donde, de forma literaria, se construye al otro como alteridad de la diferencia 
racial propia del colonialismo criollo. "Concluida la cena, los esclavos ${ }^{9}$ levantaron los manteles, uno de ellos rezó el Padre nuestro, y sus amos completamos la oración" (1988, p. 6). Esta sola frase encierra todo el lugar social de la enunciación en la novela que abarca la religión que tanto amos y esclavos deben seguir; la posición que cada uno debe ocupar en la distribución del trabajo; la jerarquización de la sociedad del momento, pero que ha continuado reproduciendo y aprendiéndose en las escuelas año tras año a través de la lectura idealizada, emblemática y sin reparos de la novela María, en la que parte de los colombianos siguen viendo representada su nacionalidad, es decir, la continuación de su colonialismo, su imaginario europeo identitario. El programa narrativo de la novela sugiere la conversión de todos los sujetos sociales al catolicismo, ya sean blancos, negros, mulatos, mestizos o indígenas aborígenes (para los que realmente no se dedica una sola línea en la novela). La idea de una educación laica fue, al decir del historiador Otto Benites, una lucha que no se logró ganar durante el siglo xIX, pues no "hubo forma de hacer entender que el laicismo no era el ateísmo" (Zalamea, 1989, p. 166), y mientras la Constitución de 1863 promovía la libertad de culto, en la práctica se consideraba que le "la escuela primaria era el segundo bautismo del hombre” (p. 166).

Como máquina de alteridades la modernidad, de la cual es constitutiva la colonización, la novela María construye un imaginario del lugar social del esclavo negro, pese a que la Ley de 21 de mayo de 1851, Sobre la Libertad de Esclavos, rezaba:

"Desde el día 1. ${ }^{\circ}$ de enero de 1852 serán libres todos los esclavos que existan en el territorio de la República” [...] "El comprobante de la libertad

9 “El estado del Cauca (actuales departamentos del Chocó, Valle y Cauca) fue uno de los más importantes centros de concentración de mano de obra esclava. Además de la minería, esta fuerza laboral se desempeñaba principalmente en la agricultura (especialmente de la caña de azúcar) y el servicio doméstico. La abolición de la esclavitud tuvo lugar en Colombia en 1851, lo cual ubica la novela anterior a esa fecha. La descripción que hace Isaacs de este tipo de escena familiar con su cotidiana jerarquización de las relaciones (padre-primogénito-madre-hijas y niños) y con la contraparte ritual de esa jerarquía (esclavo-amo), descubre el orden social terrateniente-esclavista que la novela plasma e idealiza" (nota al pie de página en la edición de Planeta, 1988, p. 6). de cada esclavo será la carta de libertad expedida a su favor con arreglos las leyes vigentes [...] ningún esclavo menor de 45 años será evaluado en más de mil seiscientos reales si fuere varón, $y$ de mil doscientos reales si fuere hembra; $y$ ningún esclavo mayor de 45 años será avaluado en más de mil doscientos reales si fuere varón, y de ochocientos reales si fuere hembra". (Hilario, citado por Zalamea, 1989, p. 183)

Pese a estas legislaciones aparentemente vigentes para los momentos previos en los que sale publicada por primera vez la novela María (1867), su relato no es acuse romántico por la libertad de los esclavos, una gesta racional por su igualdad de derechos, sino una legitimización del estatu quo. Si ya como puede leerse a lo largo de la propia Ley hay discriminación entre hombres y mujeres negros, la novela solo se limita a patrocinar un aparente buen trato, amoroso, pero vigilante por parte de sus amos blancos. Los negros continúan en la servidumbre con fidelidad, como cuando Efraín relata que, antes de su partida, Pedro, "el buen y fiel ayo, no debía encontrarlo: él había derramado lágrimas al colocarme sobre el caballo el día de mi partida para Bogotá, diciendo: amito mío, ya no te veré más" (1988, p. 9). De igual manera, el ejercicio de la esclavitud queda naturalizado como base de la producción económica, bien en las labores domésticas o ya sea en las labores del campo; Efraín narra que escuchaba "las castrueras de los esclavos que volvían espaciosamente de las labores con las herramientas al hombro" (p. 9). La narración está plagada de gestos y palabras de benevolencia por parte del amo y de sumisión por parte del esclavo, como queda demostrado en el siguiente diálogo entre el padre de Efraín y Bruno que desea casarse y pide la aprobación del amo, en el que además puede leerse cómo el amo patriarca es el garante de ejecutar los principios del programa católico: confesión y matrimonio, impuestos desde luego al esclavo negro de origen africano:

—Conque, Bruno, ¿ todo lo de tu matrimonio está arreglado para pasado mañana?

-Sí mi amo- le respondió quitándose el sombrero de junco y apoyándose en el mango de su pala. 
¿Quiénes son los padrinos?

—Ña Dolores y Ñor Anselmo, si su merced quiere.

-Bueno, Remigia y tú estaréis bien confesados.

(p. 9)

Los capítulos XL al XLIV son relevantes para comprender la forma como se construye al otro, especialmente en lo que se refiere al negro. Al parecer, la inclusión del relato de la vida de la africana Nay, ahora Feliciana, dentro del relato de la novela, le sirve a Efraín para mostrar toda la benevolencia del amo, pero además los rituales y costumbres de un mundo aún no civilizado. Cuando ella enferma de hepatitis, antes de su muerte, dice Efraín:

Di orden para que se aumentase el número de esclavas que le servían; hice colocarla en una pieza más cómoda, a lo que ella se había opuesto humildemente, y se mandó el sacerdote al pueblo. (p. 116)

Todo el orden queda subsumido bajo las estructuras del amo y la parroquia, con su cura a la cabeza. En la estructura social de la novela María no existen ciudadanos sino feligreses.

\section{Conjetura sobre la novela $L a$ casa de las dos palmas}

La novela La casa de las dos palmas (1988), del escritor Manuel Mejía Vallejo, es una novela que evalúa la herencia colonial del final del siglo xix, e inicio $\mathrm{y}$ mediados del siglo $\mathrm{xx}$, a partir de la representación de tres hechos históricos importantes: la colonización antioqueña, la Guerra de los Mil Días y la mixtura cultural entre localismo y europeísmo. A través de la rememoración de los héroes se resalta la importancia del hombre antioqueño en la construcción de la nacionalidad colombiana.

\section{Contextualización}

El autor de esta novela, Manuel Mejía Vallejo, nació en 1923 en el municipio antioqueño suroccidental de Jericó. Su niñez transcurrió rodeada del ambiente rural antioqueño, especialmente del municipio Jardín (al sur de Jericó), con sus padres. Se habla,
El cronotopo del siglo xix a través de dos novelas de la tradición literaria colombiana: María (1867) de Jorge Isaacs y La casa de las dos palmas (1988) de Manuel Mejía Vallejo Edilson Silva Liévano, David Alejandro Roa Ramírez

desde muy joven, de una afición apasionada por la literatura, con cartas extensas y bien elaboradas a su madre y con pequeños poemas que se publicaban en el periódico escolar. Terminó su bachillerato en 1943. En 1944, inició sus conocidos estudios inconclusos de Escultura y Dibujo en el Instituto de Bellas Artes de Medellín, que se evidencian como elementos fundamentales dentro de sus obras.

A lo largo de su vida, Mejía Vallejo ocupó varios cargos con gran importancia cultural, se desempeñó como periodista, director de la Casa de Cultura de Medellín, director de la Imprenta Departamental de Antioquia, director de la emisora y la imprenta de la Universidad de Antioquia y docente en las áreas de literatura de diversas instituciones. En todos estos cargos sobresalieron sus intenciones de reivindicar la tradición literaria antioqueña mediante antologías y recopilaciones, especialmente de cuento. Su trabajo como director de la Casa de Cultura tuvo su final en 1948, debido a su presunta participación en los desórdenes nacionales provocados por el asesinato de Jorge Eliécer Gaitán el 9 de abril. Poco después, se marchó del país a causa de la violencia política. Su recorrido duró cerca de siete años, vividos entre Venezuela, Guatemala y San Salvador, y durante los cuales, por supuesto, no cesó su producción literaria: Al pie de la ciudad y La muerte de Antonio Canales son dos de sus cuentos más conocidos de esa época y además galardonados en concursos.

El escritor regresa a Colombia en 1957 y se instala en la ciudad de Medellín. El estar constantemente galardonado en algún concurso de cuento lo convirtió, cerca del año 1963, en uno de los autores más importantes de este género a nivel nacional, y quizás el más importante de la región. Su época de consagración como escritor está marcada por la aparición de sus novelas El día señalado, Las mujeres ajenas y Aire de tango, que recibieron reconocimientos en diversos concursos. La casa de las dos palmas (1988) recibió el premio Rómulo Gallegos en 1989. Mejía Vallejo recibió un doctorado honoris causa de la Universidad Nacional, y la Orden al Mérito Literario en Cali. Sus últimos años los vivió en las zonas rurales aledañas a Medellín. El universo 
cultural interiorizado del autor se ve representado en sus obras, que recogen las tradiciones culturales de una Antioquia rural y urbana, de la cultura de la colonización paisa. El pueblo Balandú, centro de su cronotopo literario en La casa de las dos palmas (1988), concretiza la experiencia de lo rural y muchas características de las prácticas socioculturales propias de la región y de la época. Manuel Mejía Vallejo murió en 1988.

\section{La colonización antioqueña}

Un trabajo doctoral del norteamericano James Parsons examina ampliamente el proceso histórico que envuelve la colonización del occidente de Antioquia. Su trabajo se publica en el año 1949 y es traducido y publicado en 1950. En el prólogo de esa versión en español, Emilio Robledo hace una importante aclaración en lo que respecta al término colonización, valiéndose de la definición que hizo la Academia Española:

Colonia: "Gente que se establece en un territorio inculto del mismo país, para poblarlo y cultivarlo. Este territorio". "Colono: labrador que cultiva y labra una heredad por arrendamiento y suele vivir en ella". En tal virtud, no habrá de echarse a mala parte el título que el señor Parsons adoptó para su monografía, pues ella convence que, efectivamente, el antioqueño se ha establecido en un vasto territorio del occidente de Colombia, lo ha poblado y cultivado. (1950, p. II)

El fenómeno de la colonización antioqueña data de finales del siglo XVIII, con una vasta manifestación en el siglo XIX. Consiste en una expansión de la población por diversos territorios que abarcaron los hoy conocidos departamentos de Antioquia, Caldas, Quindío y la región norte del Tolima y del Valle del Cauca ${ }^{10}$. A pesar de su gran expansión, el

10 A mediados del siglo xix y en entre los dos periodos de tres reformas constitucionales muy importantes, la de 1853 de orientación federal, la de 1863 de orientación liberal y la de 1886 de orientación conservadora, Colombia estaba dividida en estados y no en departamentos, como actualmente: "En esa etapa de los radicales, se crearon los estados de Panamá, 1855; Antioquia, 56; Santander, 57; y Cauca, Cundinamarca, Boyacá, Bolívar y Magdalena en el mismo año. En el 61 El Tolima. Es decir se hace la integración nacional. Era una acción muy dinámica en todos los frentes de la patria" autor hace énfasis en el hecho de que la presencia más fuerte de la cultura antioqueña se encuentra en su cuna, en las montañas de Antioquia. Este proceso de expansión trajo diversas consecuencias, que van desde lo demográfico e impactan lo económico y sociocultural.

Como causa general se encuentra el descontento por la situación precaria que dejó la colonia y que evidenciaba un gran atraso en la región a pesar de su notable potencial para la explotación de las minas de oro. Juan Antonio Mon y Velarde es uno de los hombres importantes en la historia de la región, que propuso iniciativas que pretendieron mejorar las dinámicas económicas. $\mathrm{Al}$ respecto, Parsons señala:

El oidor Juan Antonio Mon y Velarde, aunque solo permaneció en la provincia durante tres años, ha sido llamado "El Regenerador de Antioquia”. Sus reformas económicas, jurídicas y de vasta influencia social, removieron la aletargada comunidad y la tornaron activa. Nuevas ciudades, los primeros y verdaderos establecimientos agrícolas en la provincia, fueron fundados en las altiplanicies más frías y libres del paludismo, y se ofrecieron bonificaciones por la introducción de nuevos cultivos. Se vigorizaron las disposiciones contra la vagancia; los holgazanes fueron enviados a servir en las nuevas poblaciones y a cultivar los nuevos campos. (1950, p. II)

El proceso de colonización estuvo acompañado además por un desarrollo moderno de la minería que, según el autor, comienza en 1825, con el descubrimiento del molino de pisones y la entrada de empresas internacionales a manejar esta área económica. La colonización antioqueña se extendió especialmente hacia el sur y el occidente. Las primeras incursiones en terrenos baldíos se dieron en 1787, con un grupo de aventureros que, en busca de la leyenda de abundante oro en los sepulcros indígenas, así como por falta de tierras y gran pobreza,

Morales, Benítez Otto. “La generación radical y la modernización del Estado colombiano" En Antología del pensamiento colombiano, Bogotá: Banco de Colombia, Alberto Zalamea (dir.) (1998, p. 171). En la actualidad, Colombia está dividida en 32 departamentos descentralizados administrativamente que integran unidades territoriales llamadas municipios y territorios indígenas y se gobierna bajo la Constitución de 1991. 
exploraron la región de Sonsón, al sur de La Ceja, sur de Antioquia. Sus primeras comunicaciones dicen:

Nosotros, los suscritos vecinos de la ciudad de Rionegro y del Valle de San José de Marinilla, venimos ante vos con toda humildad... y declaramos: hemos sido llevados a este movimiento por nuestra extrema pobreza en bienes materiales y por la escasez de tierras, ya para cultivarlas como propias o en las cuales construir habitaciones para nosotros y para nuestras familias. Así hemos venido, sin dinero, a estas montañas de Sonsón, donde hay buena tierra, amplios pastos para nuestros ganados, salinas y ricas minas de oro, a hacer nuestras casas y erigir una nueva población. Esto traerá beneficios tanto para nosotros como para el Real Tesoro... Como resultado del descubrimiento de dichas salinas y aluviones de oro y por la apertura de comunicaciones entre el nuevo plantío y Mariquita, que está cerca del dicho Valle de Sonsón. (Parsons, 1950, p. 739)

La repartición de tierras resultó en gran parte problemática, pues al tratarse de terrenos baldíos, varias partes hacían reclamaciones sobre ellas. Varias concesiones de tierras fueron realizadas a grandes terratenientes, como la realizada a Felipe Villegas en 1763; o la que la Compañía Gonzáles y Salazar disponía en el territorio recién fundado de Manizales. Así, la problemática se daba en el momento en el que los nuevos pobladores, en busca de mejores posibilidades de vida, se asentaban en los territorios propios de esas concesiones; como parte de acuerdos, se vendieron y otorgaron pequeñas cantidades de terreno por familias.

El gobierno impulsó campañas que promovían la exploración y asentamiento de poblaciones en nuevos territorios, pues implicaba un mejoramiento para la economía nacional a partir del trabajo de la tierra. Así, eran concedidos legalmente terrenos para ser poblados y trabajados, como también para construir caminos. Es importante resaltar la importancia de la iglesia en los procesos de fundación de los pueblos, cuyo establecimiento era casi simultáneo al de las comunidades. Un nuevo pueblo, una nueva iglesia, que prácticamente reproducía el acto fun- dante de la colonización española. Para el caso del Quindío, algunas nuevas circunstancias aparecen:

La rápida e inigualada ocupación ha sido llamada con propiedad "la épica de la colonización antioqueña”. El prolongado fervor de las gentes montañeras del norte, deseosas de colonizar estas tierras, parece haberse intensificado aquí por cuatro atractivos a lo menos, a saber: caucho, oro, alto precio de los cerdos, y las ventajas de la región como refugio para librarse de las guerras civiles que desolaban la república. (Parsons, 1950, p. 82)

De una manera concreta, Parsons señala:

La corriente principal de la colonización antioqueña en el siglo xIx, fue irresistiblemente hacia el sur y el suroeste, no obstante existir atrás tierras templadas extensas y desocupadas hacia el oriente, el norte y el oeste, que podían ser igualmente ocupadas. Los altiplanos saludables de Rionegro suministraron a los primeros y más numerosos colonos; y en las montañas de Sonsón estaban algunas de las tierras ocultas disponibles. [...] Por añadidura, allí estaban los atractivos justificados de las minas y sepulturas indígenas, y también el caucho del Quindío. A medida que la colonización se extendía hacia el sur, se acercaban entre sí más y más Bogotá, Cartago, Cali y Popayán. Como consecuencia de esto se iban presentando más oportunidades para el desarrollo económico con el consiguiente aumento del comercio, lo cual, a su turno, estimulaba la construcción de caminos de peaje. Finalmente, hubo cierta inercia en el movimiento colonizador, el cual, una vez orientado hacia el sur, trató de seguir hacia delante, en la misma dirección inicial. (1950, p. 95)

Con la colonización antioqueña del occidente colombiano nos encontramos con un proceso que culminó en una organización poblacional que difería del típico latifundismo latinoamericano de la época, es decir, en esta región (para esta época) no se habló de grandes terratenientes sino de pequeños propietarios que trabajaban su tierra.

\section{Desarrollo de la segunda conjetura}

La novela La casa de las dos palmas (1988) se inicia con el regreso de Efrén Herreros al pueblo Balandú, 
un pueblo fundado por su padre y sus abuelos durante la colonización antioqueña. La novela está narrada a partir de relatos de la memoria fragmentados que van reconstruyendo la historia de toda la vasta familia de los Herreros, los fundadores del pueblo; y de cuya progenie se derivan los aparatos de la reciente sociedad: político, eclesial, militar y civil. Enrique Herreros, por ejemplo, fue coronel en la guerra de los Mil Días; Pedro José Herreros, tío de Enrique, Efrén y Rodrigo, era el obispo del pueblo.

La imaginería del pueblo de Balandú está signada por las creencias morales católicas que son contrarias a las creencias de Efrén Herreros, quien toma distancia al recoger a su nuera que ha sido abandonada por Medardo, su hijo, y tildada de prostituta. Así que se propone rehabitar la Casa de las dos Palmas, que había sido construida por su tío Juan Herreros con las ganancias de una mina de oro, para conquistar el amor de Isabela, sin que este se concretara alguna vez. La narración, que es más una rememoración constante, fluctúa entre el pasado y el presente históricos de la novela, lo que la hace fragmentada, llena de pliegues donde los personajes, unos y otros, aportan a la reconstrucción de la memoria. Esta estrategia narrativa permite inferir diferentes imaginerías de la época que en lo general se debaten entre la concepción cristiana, como la del personaje Zoraida Vélez: "Mis hijas, que sean limpias de alma, sanas de cuerpo, que la mancha nunca llegue a su mirada, muerta antes que pecadoras" (Mejía Vallejo, 2013, p. 23), o una visión más liberal como la de Efrén Herreros. Igualmente, los personajes se mueven entre la imaginería fantástica de almas en pena, judíos errantes, curas sin cabeza, brujas, pecadores, condenados, maldiciones hereditarias, etc., que siempre han marcado la cultura colombiana (sin que pueda afirmarse que exclusivamente rural) del siglo xIx o del xx, premoderna o moderna. Se trata, entonces, de un elemento constitutivo de la mentalidad maravillosa o de la imaginería colombiana.

La reconstrucción de la casa así como la constante rememoración de las obras de los fundadores permiten al narrador omnisciente de la novela construir una imagen simbólica del proceso de moder- nidad en Colombia. Si la colonización es constitutiva de la modernidad y la ciudad fue a gran escala la forma como las colonias lograron dominar un vasto territorio como el de América Latina, pues a través de ellas crearon una extensa red de dominación jurídico, militar, económica, ahora es el turno para el pueblo como continuidad de la colonización interna, esta vez por criollos de quinta o décima generación. Balandú es la imagen de ello y lo que se narra a través de lo que viene a la memoria son las historias de héroes dignas de ser recordadas o rememoradas:

—Este puente lo hizo mi abuelo

El pueblo de donde se iba era de su familia.

-Ellos trazaron los caminos. Ellos hicieron pueblos y caminos.

De piedra y de barros las trochas a las tierras encaramadas, brotantes las raíces de roble y palosanto. (p. 33)

Mi abuelo construyó la fábrica a orillas del San Juan. A estas aguas los indios las llamaban Docató, río de los yuyos. (p. 35)

La narración acerca de la Casa de las dos Palmas sirve al autor para objetivar lo histórico del carácter colonizador de los paisas: "Mansión imponente, asentamiento y confirmación de un poderío, descanso grande en la trepada, mirada larga en el orgullo de ser dueños" (p. 37). No hay colonización sin ocupación, pero además opera como espacio de la colonialidad en que una mentalidad se objetiva a través de sus símbolos. Esto queda demostrado por el gusto burgués de la novia de Juan Herreros, el piano, para lo cual el colono hace traer uno desde Europa: "Por estas breñas lo hizo traer don Juan Herreros, a ella dizque le gustaba la música”.

Otro de los elementos importantes relacionados con la fundación del pueblo es la metáfora de la patria chica asociada a la nacionalidad: "El hombre no puede carecer de una patria pequeña porque carecerá de antecedentes, de amistad verdadera. Carecerá de lenguaje" (p. 47). Para algunos pensado- 
res del siglo XIX, como Salvador Camacho Roldán, "la nacionalidad" se define como:

Un territorio circunscrito y una familia humana que toma posesión de él para buscar sustento y levantar hogares permanentes; un hombre y una propiedad, un ser fisiológico y un ser metafísico, forman, por medio de un místico consorcio, la primera base de una nación. Organización política para proveer al ejercicio de las diversas funciones, organización industrial para alimentarlas, organización civil para mantener la paz, organización militar para defenderlas, organización intelectual para desarrollarlas, construyen la armazón del edificio. (Zalamea, 1989, p. 204)

Así que la familia Herreros es la encarnación de ese programa de nacionalidad. La familia Herreros no solo funda un pueblo, sino una organización que cubre todos los ámbitos e instituciones: “[...] siempre Los Herreros infundían respeto. Desde los Fundadores. Desde Mariano el Alcalde ciego. Desde el coronel" (Mejía Vallejo, 2013, p. 17). A esto se suman Pedro José Herreros, el obispo; Efrén Herreros, que en lugar de estudiar medicina prefiere ser coronel en la Guerra de los Mil Días; y abogados, que se ajustan a las necesidades del colonizador Rodrigo Herreros: "Yo necesito un abogado que sepa interpretar mi ley". Lo cual ha sido una constante en la nacionalidad colombiana, en donde la ley no hace justicia, sino que se ajusta al poder, se repliega en el estamento.

La colonización es, a su vez, la historia de otro de los grandes problemas en Colombia, que se funda con la llegada de los españoles y continúa hasta nuestros días, como lo es el desplazamiento:

Había baldíos aún, viejas montañas del indio, desplazado cada vez más hacia otras selvas; el avance era un derecho tomado, no dolía la injusticia al practicarlo, también la tierra y el hombre debía pagar su tributo obligatorio, imponían la ley del arrasamiento creador, según su ángulo de enfoque. (p. 145)

La imagen robusta arquetípica del fundador es la imagen del "principio de autoridad" que tanto se va a defender hacia finales del siglo xix y que dará como resultado la Constitución conservadora de 1886.

La voz fundadora del padre, su olor a macho colonizador, su barba retorcida, sus ojos son concretos, sus brazos al horizonte en acto de creación. El retraimiento de Enrique el mayor, su rebeldía, su distancia. Nunca podría con él. Nacía el odio prematuramente. (p. 146)

Este hijo que se niega a seguir las directrices de su padre, quien desea que sea médico porque su institucionalidad así lo necesita, preferirá luchar en la Guerra de los Mil Días de la cual hay alusiones directas en la novela. Por ejemplo, la mención de personajes históricos como el general Rafael Uribe Uribe $^{11}$.

El fantasma de la guerra es otro de los elementos constitutivos del siglo XIX, del $\mathrm{xx}$ y lo que llevamos del Xxi. Cabe hacer una breve semblanza de sus orígenes. Mariano Ospina Rodríguez (1849) escribe al respecto:

El partido de la independencia tuvo la desgracia de dividirse cuando más necesitaba la unión. La forma de gobierno que debía darse en el gobierno fue la causa de la discordia. Quisieron unos la federación, otros el centralismo; y después de tres siglos de paz, esta fatal contienda hizo correr por primera vez la sangre entre hermanos y dio un

11 Rafael Víctor Zenón Uribe Uribe (Valparaíso, Estado Soberano de Antioquia, 12 de abril de 1859 - Bogotá, 15 de octubre de 1914) fue un abogado, periodista, diplomático y militar colombiano. Murió asesinado en las afueras del Capitolio Nacional. Uribe Uribe es más conocido por su ideario político a favor de la instauración de un socialismo de carácter corporativo y sindicalista en Colombia estructurado y explicado en 1904, así como por su labor diplomática y a favor de los cafeteros colombianos en el combate de las enfermedades tales como la roya. Uno de sus grandes aportes fue, junto con Benjamín Herrera, la fundación de la Universidad Republicana que más tarde se convertiría en la Universidad Libre de Colombia. Uribe Uribe combatió en las guerras civiles de 1885, 1895 y 1899, de las cuales saldría derrotado. Su papel como general estaría marcado por importantes victorias durante la Guerra de los Mil Días desde el punto de vista táctico, las cuales le dieron una reputación como el principal general liberal a pesar de no tener la preparación militar de otros como Benjamín Herrera. Aun así, Uribe Uribe sufrió importantes derrotas al mando de los ejércitos liberales, como en la batalla de Bucaramanga (1899) y la pérdida de Coroza. (Disponible en http://es.wikipedia.org/wiki/Rafael_Uribe_Uribe, recuperado el 22 de junio de 2014) 
golpe funesto a la causa de la independencia y de la república. (Zalamea, 1998, p. 224)

Un balance que hace Rafael Núñez (1882), autor de la Constitución de 1886 junto a Miguel Antonio Caro, resulta muy particular. Tras las gestas de consolidación de la Independencia, que van de 1810 a 1821, solo entre los años de 1845-1849 y 1853-1857 se goza de completa paz, los demás años están marcados por guerras civiles bajo la denominación de revoluciones, asonadas o revueltas. Núñez contabiliza 12 guerras civiles y un golpe de Estado: "En el curso de los 40 años escasos que llevamos de vida política desde 1832, el mantenimiento del orden público ha sido, pues, la excepción y la guerra civil, la regla general" (Zalamea, 1998, p. 248). Es importante destacar que estas guerras civiles están profundamente ligadas al caudillismo político de la época, que otorgaba las directrices para la guerra que luego se ejecutarían en el campo y con los campesinos. El origen de la violencia en Colombia es política y así resulta evaluada en la novela La casa de las dos palmas a través de la mención de la Guerra de los Mil Días, entre 1899 y $1902^{12}$.

Así que el hijo se revela al principio de autoridad de su padre para simbolizar el carácter revolucionario de las guerras civiles de finales del siglo XIX:

-Seré Guerrero.

Llenó su cuarto de libros de historia, revueltas, asonadas, revoluciones, guerras, el duro rostro humano.

${ }_{-}$iPresente, mi General Uribe!

12 La Guerra de los Mil Días fue una guerra civil de Colombia disputada entre el 17 de octubre de 1899 y el 21 de noviembre de 1902, en un principio entre el Partido Liberal y el gobierno del Partido Nacional en cabeza del presidente Manuel Antonio Sanclemente, quien fue derrocado el 31 de julio de 1900 por José Manuel Marroquín Ricaurte, representante del Partido Conservador, en alianza con el liberal Aquileo Parra; a partir de entonces, y a pesar de dicha alianza, la guerra continuaría entre liberales y conservadores. Esta guerra se caracterizó por un enfrentamiento irregular entre el ejército gubernamental (en un principio nacionalista, después conservador) bien organizado y un ejército de guerrillas liberales mal entrenado y anárquico. (Disponible en http://es.wikipedia.org/ wiki/Guerra_de_los_Mil_D\%C3\%ADas.)
La inocencia, el deber no impuesto, el ardor de unos años sin meta. El sacrificio era como un llamado.

$[\ldots]$

El padre observaba, atento en su indiferencia de forma.

- Militar o no militar, va a sufrir este muchacho

Lo veía leer periódicos que llegaban de La Casa del Río, tomos de historia, comunicados que anunciaban otra guerra civil. (2013, p. 149)

Enrique Herreros es esa cuota de guerrero nacionalista que va a la guerra en la que, además, se hacía hombre; una guerra desigual del despojo del otro, cuyas tecnologías serían el caballo, la trinchera, el machete o la escopeta. Así es como lo describe el narrador de la novela: "la epopeya del pueblo anónimo, dirigido por aristocrizantes cerrados o por caudillos con más ideas generosas que capacidad para plantear estrategias guerreras" (p. 244). Sin embargo, el hecho de que Enrique Herreros haya estado del lado del general Uribe plantea tácitamente una república que jamás ha podido ser, contraria a la de su padre que defendía el nacionalismo colonial, su hijo optaría por ideas contrarias al estatus quo, que desde la Constitución de 1886, de Núñez y Caro, había retomado la hegemonía conservadora como ideología.

Esta guerra civil se originó a partir de la batalla política de las reformas constitucionales, inestables y sucesivas durante el siglo XIX, y que Rafael Núñez (1882) evalúa:

La Constitución de 1832, medianamente central; la Constitución de 1843; rígidamente autoritaria; la Constitución de 1853, casi federal; la Constitución de 1858, completamente federal y al de 1863 , que fue en el camino de la descentralización hasta reconocer como principio fundamental de la organización política la soberanía de las secciones. (Zalamea, 1998, p. 248)

La Constitución de 1863, síntesis de lo que se conocería como la República Liberal, es exaltada 
por unos por su grado de tolerancia, por impulsar la economía, la defensa de la vida, el matrimonio civil, la educación laica, acabar con privilegios administrativos y legales, y por haber acabado con la propiedad de manos muertas en manos de las corporaciones religiosas. Es, pues, al decir de Otto Benítez, un logro para el Estado moderno colombiano, pues hasta entonces:

El régimen feudal estaba vivo en muchos de sus aspectos más odiosos e intolerables. La familia, la propiedad privada y las relaciones entre los domésticos y los señores seguían aferradas a la tradición española y el poder temporal del clero continuaba absorbiendo y sacando de la libre circulación los escasos elementos de riqueza que alimentaban la anémica economía nacional. (Zalamea, 1989, p. 174)

Es importante señalar que a la par del pensamiento liberal se alzaba toda una diatriba de pensamientos a favor y en contra. Una vez, por ejemplo, quizá por considerarla permisiva, el joven pensador Miguel Antonio Caro (1869) escribió un artículo titulado "La sociedad es una gran familia", donde parece coincidir con lo que la novela María representa como relato de nación y que va en completa contravía de lo que fue la República Liberal:

El hombre es un ser social; la asociación le es un deber; la misión del hombre es perfeccionamiento del hombre; esta misión se cumple mediante el poder; este poder lo cumplen los favorecidos por la naturaleza; estos tiene el deber de constituirse en auxiliares de Dios y la naturaleza; deben trasmitir la enseñanza divina ilustrando a los entendimientos y reformar y ampliar la de la naturaleza por medio de sensaciones equitativamente distribuidas. Gobernar es educar; educar, perfeccionar. Tal es el deber del hombre, individual y colectivamente. (Zalamea, 1998, p. 198)

El proyecto de derrocar la Constitución de 1863, la más liberal que se haya tenido durante el siglo XIX, triunfará finalmente con la Constitución de 1886, escrita por Miguel Antonio Caro y Rafael Núñez. Así lo resume otro pensador de la época de inicios del siglo xx, Rafael María Carrasquilla (1909) en el artículo titulado "El señor Caro":

El sentir de Núñez y de Caro triunfó en 1886, con la expedición de la cristiana Constitución, bendecida por León XIII y que, en lo sustancial, es obra de Caro. Esta carta tiene, de seguro, defectos, como toda obra humana; pero ciego ha de estar quien no reconozca que devolvió la unidad a la patria, la paz a las conciencias [...]. (Zalamea, 1989 p. 240)

Desde entonces, el pensamiento conservador volvió a erigirse en el poder, lo cual provocó la guerra civil de los Mil Días, además de repercusiones en todos los aspectos de la vida a lo largo del siglo $\mathrm{xx}$, tanto así que Colombia es uno de los países latinoamericanos que no tuvo vanguardias literarias.

\section{Discusión}

En la reconfiguración del proyecto de Estado y el relato de nación durante el siglo XIX, no hay duda de que los intelectuales de todas las disciplinas recientes desempeñaron un papel relevante. Según puede inferirse tras la lectura de obras como María (1867), del intelectual Jorge Isaacs, que lo hace no solo desde su ejercicio político, sino también desde el punto de vista que adquiere su tarea de tropologizar la historia, de volverla un relato ejemplarizante para la subjetivación de sus lectores, su contribución es mayor desde la representación cuando esta se convierte en lectura obligada, nacional, fundante y canónica para la lectura en todas las escuelas. A esta conclusión han llegado investigaciones recientes, como la de Miguel Ángel Urrego, quien afirma que la configuración del relato de nación para el caso colombiano tuvo tres componentes esenciales durante el siglo xix: "La centralidad de la Iglesia en el orden social y político; una recreación paternalista, clasista y racista de lo popular; y la consolidación del cachaco $^{13}$ como arquetipo nacional" (2002,

13 Es un adjetivo para denominar al bogotano(a) u hombre o mujer del interior. Sin embargo, el prototipo de hombre cachaco, que se diferencia del hombre bogotano por un dialecto particular y unas prácticas propiasdel siglo XIX, aparentemente está en vía de extinción. El DRAE lo define como: “Adj. amer. [Joven] elegante, servicial y caballeroso: tiene un pretendiente muy cachaco; 2$) \mathrm{m}$. amer. Lechuguino, petimetre: no hay quien aguante a un cachaco como 
p. 17). Las dos primeras conclusiones coinciden con la descripción que hacíamos sobre el cronotopo del siglo XIX, visto desde el punto de vista de esta novela, que, como ya se dijo, es una obra de la diferencia colonial. Allí el colonial criollo quiere tomar distancia del otro, su imaginario gira en torno a educarse en Europa, hacer lecturas de autores europeos, formar el gusto en referencia con Europa, diferenciarse desde la concepción de la alteridad frente al aborigen, el negro, el campesino, el esclavo.

En cuanto a la idea de que el cachaco es el arquetipo durante este periodo de tiempo, la confirma el hecho de que los colegios prestigiosos estaban en Bogotá y de la presunción de tener el mejor castellano (idea que incluso conllevaría a la construcción de la imagen de Bogotá como la "Atenas" latinoamericana). Frente al tercer componente constitutivo del campo cultural, la obra de Manuel Mejía Vallejo es precisamente una respuesta del otro eje de la cultura de final e inicio de siglo: la continuidad de la colonización. En La casa de las dos palmas (1988) también está presente esa separación de la alta cultura y la baja cultura, lo popular, pero sin rivalizar. Sus personajes igual entonan una copla, lo mismo que hacen referencia a la cultura europea, pero ahora dialogan con obras del campo de la literatura colombiana como El carnero de Juan Rodríguez Freyre; Tomas Carrasquilla (antioqueño), y la obra de Jorge Isaacs, María, que ya para el año en el que se sitúa el tiempo cronológico de la novela (1901) es citada por los personajes. Así que la obra La Casa de los dos palmas, más que una novela, es casi una epopeya de la contribución de los colonizadores y fundadores de lo que se ha denominado la colonización antioqueña, en la que se muestra cómo el hombre antioqueño, antes que ser un colonizador, es un poblador, que no se basta tan solo con crear un pueblo sino que también constituye todo un orden cotidiano, jurídico, militar, eclesial, industrial, tecnológico. Así, en el clan de los fundadores, la novela nos representa un alcalde (Mariano), un maestro (Bastidas), un abogado (Rodrigo Herreros), un obispo cínico (Pedro

él. 3) m. y f. amer. Policía: le detuvo un cachaco para identificarle. amer. Español reaccionario con situación privilegiada.
José), un coronel (Enrique), un patriarca sublimado como un amo del campo benevolente, casi un San Francisco de Asís, tal como puede leerse la última descripción que se hace de Efrén Herreros, aunque desde luego sea una metáfora de cómo el hombre antioqueño ha constituido el aporte al desarrollo colombiano:

Efrén herreros hablaba con los árboles del monte y con las flores al cultivar sus plantas; le dolía cortar la rama bajera, diciéndole cómo era necesaria la mutilación para el vigor del tronco; sostenía con su mirada el vuelo de las aves altas, y regaba arroz y maíz picado en los rastrojos para hacer más fácil la vida de los pájaros pequeños [...]. (Mejía, 2013, p. 507)

Sin embargo, las dos novelas no rompen con el statu quo, aunque algunos personajes pretendan ser liberales, contradictorios al establecimiento, como en el caso de Enrique Herreros, o incluso su tío, el Obispo Pedro José Herreros quien se comporta en oposición al dogma. Sus personajes están plenamente vinculados al orden social establecido. Evangelina Herreros, hija de Efrén Herreros, que ha decidido divorciarse de su esposo, hacia las líneas finales de la novela, espera una respuesta del Vaticano para que anule su matrimonio con Aníbal Gómez, pues la proclama es "lo que ha unido Dios que no lo separe el hombre": "Hay causales suficientes para que el Vaticano acepte la anulación’ - había dicho Rodrigo el abogado, sufridor también de su sobrina" (p. 502). Lo cual es un indicio de que la estructura social religiosa cristiana ha vuelto a ser dominante, sobre todo después de la Constitución de 1886, hasta nuestros días.

\section{Referencias}

Bajtín, M. (1975). Las formas del tiempo y del cronotopo en la novela, En Historia Contemporánea de América Latina. Santiago de Chile: UARCIS, (S.A). Bajtín, M. (1989). Teoría y estética de la novela (1975). Madrid: Taurus.

Castro Gómez, S. (2003) "Ciencias Sociales, violencia epistémica y el problema de la invención del otro" en La colonialidad del saber: eurocentrismo y ciencias 
sociales. Perspectivas latinoamericanas. Buenos Aires: CLACSO, UNESCO.

Isaacs, J. (1988). María (1867). Bogotá: Planeta Editorial Colombiana. S.A.

Mejía Vallejo, M. (2013). La casa de las dos palmas (1988). Medellín: Concejo de Medellín, Biblioteca Pública Piloto de Medellín para América Latina.

Mignolo, D. W. (2000). La colonialidad a lo largo y ancho: el hemisferio occidental en el horizonte colonial de la modernidad en. La colonialidad del saber: eurocentrismo y ciencias sociales. Perspectivas latinoamericanas. Buenos Aires: CLACSO-UNESCO

Molina, Londoño, L., F. (2001).La industrialización de la minería de oro y plata en Colombia en el Siglo XIX: sociedad de Zancudo y compañía minera de Antioquia. Recuperado el 12 de abril de 2014. En enhttp://www.banrepcultural.org/blaavirtual/ revistas/credencial/junio201

Parsons, J. (1950). La colonización antioqueña en el occidente de Colombia. (1era Ed. En Español). Antioquia: Colombia, 1950.
Rama, A. (1998). La ciudad letrada. Uruguay: Arca.

Sommer, Doris. (2004). Ficciones Fundacionales. Bogotá: Ediciones Fondo de Cultura Económica.

Urrego, Miguel Ángel. (2002). Intelectuales, Estado y Nación en Colombia. De la Guerra de los Mil Días a la constitución de 1991. Bogotá: Universidad Central, Siglo del Hombre Editores.

Vergara y Vergara, J. Ma. (1867). Historia de la literatura en Nueva Granada (desde la conquista hasta la independencia-1538-1820) Bogotá: Imprenta Echeverry Hermanos.

White, Hayden. (2003). El texto histórico como artefacto literario. Buenos Aires: Editorial Paidós.

White, Hayden. (2011). La ficción de la narrativa. Ensayos sobre historia, literatura y teoría (1957-2007) (2010). Buenos Aires: Eterna Cadencia.

Zalamea, Alberto, Et Al. (1989). Antología del pensamiento colombiano. Bogotá: Banco de Colombia.g 